Special issue of the 2nd International Conference on Computational and Experimental Science and Engineering (ICCESEN 2015)

\title{
Determination of the Natural Radioactivity Level of Amasya Şeyhcui Region
}

\author{
A. CoşKun* And B. ÇETin \\ Amasya University, Sciences \& Arts Faculty, Amasya, Turkey
}

\begin{abstract}
People are exposed to both internal and external radiation from the natural radiation sources. For this reason, studies determining the natural radiation level are made to detect the effects of radionuclides, that constitute the natural radiation sources, on the environment and especially the effects of radiation on people and on biological systems. The most common radiation sources are ${ }^{238} \mathrm{U},{ }^{226} \mathrm{Ra},{ }^{232} \mathrm{Th}$ and ${ }^{40} \mathrm{~K}$ radioisotopes. In this study, in the samples of the rock and soil acquired from Amasya Şeyhcui Region, the activity concentrations of ${ }^{226} \mathrm{Ra},{ }^{232} \mathrm{Th}$ and ${ }^{40} \mathrm{~K}$ are determined by using $\mathrm{NaI}(\mathrm{Tl})$ detector with gamma spectrometer and are compared with the limit values.
\end{abstract}

DOI: 10.12693 /APhysPolA.130.309

PACS/topics: 28.52.Fa, 28.41.Qb

\section{Introduction}

Radioactive nuclei were created at the beginning of the universe and having long half-life, are present in the Earth's crust. The radiation due to radionuclides, which are scattered in the depths of the Earth contribute to daily natural background radiation. These generally occur in the ground-source materials (stone, soil, rocks, etc.) in different amounts. The most important part of that radiation is due to the uranium, thorium and potassium.

As natural radiation is the largest contributor to the external dose of the population, it is important to assess the gamma radiation dose from natural sources $[1,2]$. Environmental radiation originates from cosmic rays, solar rays, water and soil. Mankind will not escape from natural radiation sources in its vicinity. Thus, people are exposed to continuous radiation. Therefore it is important to measure the natural radioactivity and there have been several works performed to measure ${ }^{226} \mathrm{Ra},{ }^{232} \mathrm{Th}$ and ${ }^{40} \mathrm{~K}$ activity concentration in different materials [3].

The average annual value of the effective dose of radiation received by way of natural radiation is about $2.4 \mathrm{mSv}[4,5]$.

High-energy particles from space (protons) from the Sun are constantly bombarding the world. The density of cosmic rays near sea level due to the reduced amount of radiation exposure dose appears to be reduced.

According to UNSCEAR calculations, the annual effective dose values, resulting from cosmic rays, at ground level vary around the average of $0.4 \mathrm{mSv}[4,6]$.

The worldwide average specific activities of ${ }^{226} \mathrm{Ra}$, ${ }^{232} \mathrm{Th}$ and ${ }^{40} \mathrm{~K}$ in the Earth's crust are estimated as 50, 50 and $500 \mathrm{~Bq} \mathrm{~kg}^{-1}$, respectively $[7,8]$.

*corresponding author; e-mail: betulcetin3205@gmail.com

\section{Method and results}

In this study radioactive elements ratio of rock and soil samples taken from Amasya Şeyhcu neighborhood were measured. Collected samples were first ground in the mill in order to obtain powder and sieved and left at ambient conditions for 10 days. Then powders were dried in an oven for 24 hours at $100^{\circ} \mathrm{C}$. After drying, radiation counts of the sample containers were measured.

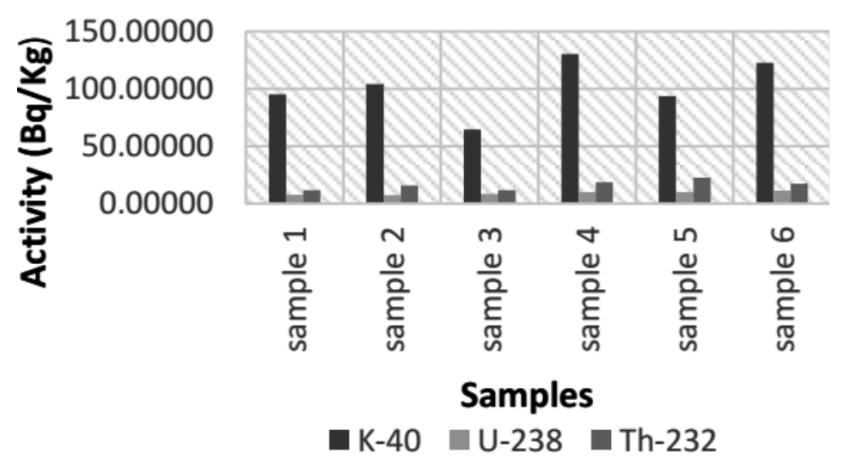

Fig. 1. Activity concentration.

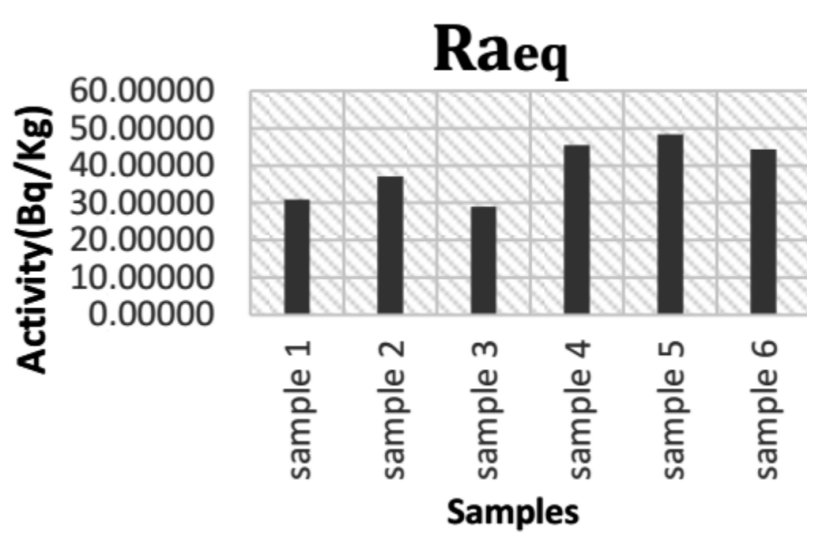

Fig. 2. Radium equivalent concentration. 
The samples were weighed and labeled. Sample containers were tightly closed and heated for a period of one month to ensure equilibrium of radon in the soil. Before the measurement of samples, $\mathrm{NaI}(\mathrm{Tl})$ detector was calibrated with previously known radioactive energy sources. Calibration was performed using ${ }^{137} \mathrm{Cs}(662 \mathrm{keV})$ and ${ }^{60} \mathrm{Co}(1173-1332 \mathrm{keV})$ radioactive sources.

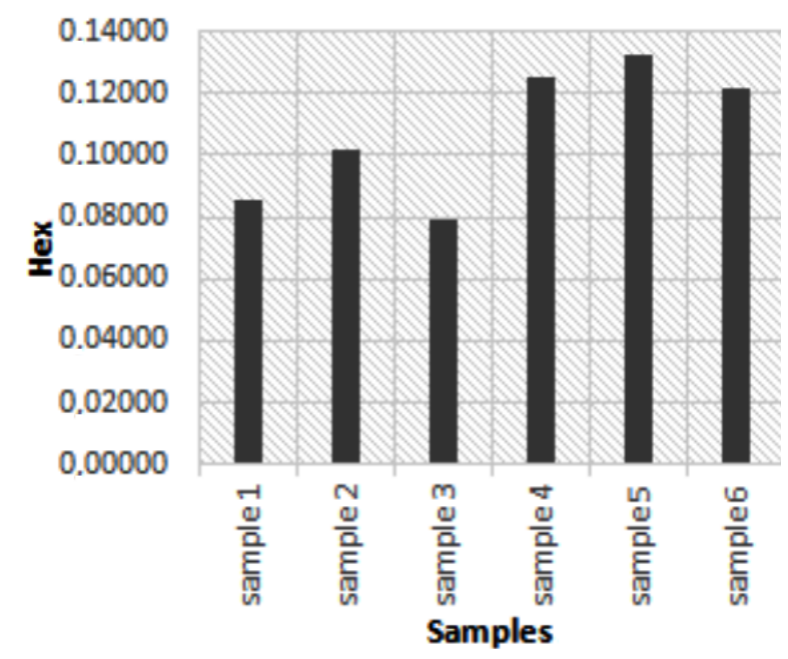

Fig. 3. Hex value.

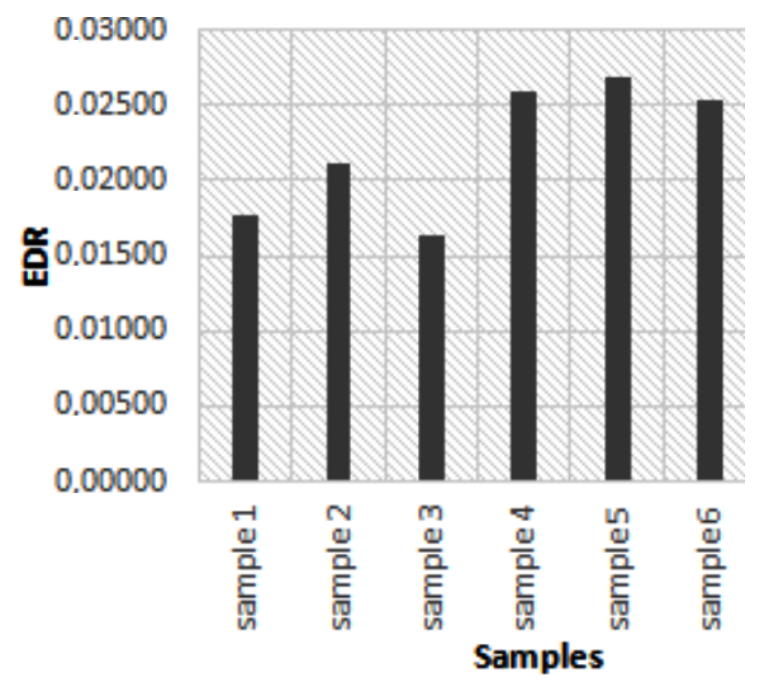

Fig. 4. Absorbed dose rate.
Then gamma radiation counts were measured for each sample during 72000 seconds using gamma spectrometry. Gamma radiation counts of empty sample cups were taken in advance to account for the background radiation level.

\section{Conclusions}

Measurement results are compared with the average values registered in the world. The obtained value of the activation of potassium element is higher then the average, whereas very low uranium and thorium activity were obtained.

\section{References}

[1] UNSCEAR, Sources, effects and risks of ionizing radiation, Report to the General Assembly with Scientific Annexes, New York 1988.

[2] İ. Akkurt, R.B. Ermış, P. Baş, K. Günoğlu, Acta Phys. Pol. A 128, B-34 (2015).

[3] İ. Akkurt, B. Mavi, H. Akyıldırım, K. Günoğlu, Int. J. Phys. Sci. 4, 403 (2009).

[4] TAEK, Radyasyon, İnsan, Çevre, TAEK, Ankara 2009, p. 3.

[5] B. Mavi, I. Akkurt, Rad. Phys. Chem. 79, 933 (2010).

[6] N.A. Uyanik, Z. Oncu, O. Uyanik, M. Bozcu, I. Akkurt, K. Günoglu, F. Yagmurlu, Acta Phys. Pol. A 128, B-438 (2015).

[7] United Nations Scientific Committee on the Effects of Atomic Radiation Sources, Effects and Risks of Ionizing Radiations, UNSCEAR Report, New York 1993.

[8] N.A. Uyanik, Z. Öncü, O. Uyanik, İ Akkurt, Acta Phys. Pol. A 128, B-441(2015). 